\title{
FDA Device Classification
}

National Cancer Institute

\section{Source}

National Cancer Institute. FDA Device Classification. NCI Thesaurus. Code C112278.

The class of medical device as determined by the US Food and Drug Administration, based upon the level of control necessary to ensure safety and effectiveness (21 CFR 860). 